\title{
Anthós
}

\section{Of Homespun Opulence: An Analysis of Jane Freilicher's Pastoral Abstraction in Parts of a World}

Grace Wolfe

Portland State University

Follow this and additional works at: https://pdxscholar.library.pdx.edu/anthos

Part of the American Art and Architecture Commons, and the Modern Art and Architecture Commons Let us know how access to this document benefits you.

\section{Recommended Citation}

Wolfe, Grace (2021) "Of Homespun Opulence: An Analysis of Jane Freilicher's Pastoral Abstraction in Parts of a World," Anthós: Vol. 10: Iss. 1, Article 3.

https://doi.org/10.15760/anthos.2021.10.1.3 


\section{Of Homespun Opulence: An Analysis of Jane Freilicher's Pastoral Abstraction in Parts of a World

\author{
Grace Wolfe
}

In the summer of 1952, Jane Freilicher and a group of friends rented a house in East Hampton, Long Island. The group, which would later become known as integral members of the New York School, spent the season writing poetry and creating art inspired by their bucolic setting. For Freilicher, it would be the motif that defined her paintings; throughout her career as an artist, Freilicher transitioned between painting the countryside of eastern Long Island to the urban landscape outside her Fifth Avenue apartment. During a period of bold abstraction and American individuality, her landscapes and still-life paintings stand out for their figurative nature. Some scholars have gone so far as to classify her realism as "willfully innocent or anachronistic." It is simple enough to observe Freilicher's work as removed from the configurations of Abstract Expressionism, to assume complacency against the highly political currents of art in cold-war America. However, upon analyzing the ways in which Freilicher manipulates her scenes to befit the world around her, it becomes clear that her seemingly traditional style is, in fact, radical. As Freilicher once said, "I'm quite willing to sacrifice fidelity to the subject to the vitality of the image, a sensation of the quick, lively blur of reality as it is apprehended rather than analyzed. I like to work on that borderline - opulent beauty in a homespun environment."2 Indeed, Freilicher used her art as her friends used poetry: to deconstruct and reinterpret individualized reality. The resulting imagery is lyrical, romantic-emulating the pastoral. In her aptly named painting, Parts of a World (fig. 1), Freilicher exhibits exactly this. Concerned with depicting not what she saw in reality but how she saw reality, Parts of a World abstracts the pastoral to express identity. This essay examines the ways in which Freilicher pulled from pastoral images of the past and translated them into her still-life through content, composition, and color.

Before analyzing pastoralism in Freilicher's work, it is imperative to first understand the complexities of the genre. Best described in Paul Alpers' seminal explication, "What Is Pastoral?" pastoralism has come to represent a construction of identity that can occur even when removed from the physicality of its inception. While the original pastoral in the poetry of the Golden Age concerns an escape to the shepherd's nature to find oneself, Alpers and other scholars have

\footnotetext{
${ }^{1}$ Robert Rosenblum, "The Withering Greenbelt: Aspects of Landscape in Twentieth-Century Paintings," Denatured Visions: Landscape and Culture in the Twentieth Century, (Harry N. Abrams: New York, 1992): 41.

2 "Opulent Beauty in a Homespun Environment: Jane Freilicher Paintings," Fine Art Connoisseur November 15, 2018. https://fineartconnoisseur.com/2018/03/fine-art-exhibition-jane-freilicherpaintings/
} 
observed its use throughout time in an array of mediums and settings, defined by "an interpretation, a selective emphasis determined by individual or cultural motives." In the works examined later in this essay, temporality affects the pastoral more than its location. Granted, nature is certainly an integral aspect of pastoralism, although as shown in the growing popularity of the urban pastoral during Freilicher's time, nature itself can become reconfigured. Abstract Expressionism benefited greatly from this adaptation, as the cultural diversity of the post-war city allowed an escape from the self just as pre-modern nature. Likewise, many of Freilicher's friends from the New York School (Frank O'Hara, in particular) constructed poetry in the same imaginative space. For the purposes of this paper, the usual discourses on the New York School have been set aside to show how Freilicher combines gestural abstraction, color field, and representational styles in radical ways that the critical establishment has otherwise largely ignored. Furthermore, while Freilicher's numerous city-scape portraits indicate an evocation of the urban pastoral, her abstract figuration in works like Parts of a World allude to a tie with even the most traditional pastorals.

Beginning with Virgil's Eclogues and Theocritus' Idylls, pastoralism remained a popular genre in Italy well into the Renaissance. ${ }^{4}$ During the growing urbanization of the $17^{\text {th }}$ century, nobility in Northern Europe sought pastoral images to escape into the mysterious, idyllic countryside. Working on one such commission from a Swiss nobleman, many of the paintings from French artist Claude Lorrain depict harmonic landscapes.

By all traditional definitions, Lorrain's Pastoral Landscape (fig. 2) is staunchly idyllic. This is best reflected not so much in its sweeping, lush nature, but more so through the configuration of the human figures that dot the piece. In the bottom right-hand corner, a man and woman rest on a fallen tree trunk. The pair are most likely shepherds; the woman holds a staff-most likely the man'sand leans in to listen as he gestures towards the mighty land his livestock graze. His arm guides the viewer to a landscape that is certainly grandeur. Soft, full trees give way to rolling meadows and a tranquil lake, all darkened in shadow as the blushing sunset tucks into the mountains. The cattle seem at peace in the beauty, just as the humans. Indeed, it is this very sense of ease that most evokes the pastoral. Each figure engages in leisurely activities: two figures quietly row a boat, one man strolls across the bridge, another rides a trotting horse. Even the shepherds recline in contemplation, their bare feet comfortably resting on the grass. In reality, the work of a $17^{\text {th }}$ century countryman was grueling and unglamorous. As Alpers mentions in the conclusion of his essay, "pastoral

\footnotetext{
3 Paul Alpers, "What Is Pastoral?" Critical Inquiry 8, no. 3 (1982): 437-60, 459.

4 David C. Ditner, "Claude and the Ideal Landscape Tradition in Great Britain," The Bulletin of the Cleveland Museum of Art 70, no. 4 (1983): 147-63, 150.
} 
representation of human life is such that realistic claims and modes are part of its repertoire." 5 The primary intention of the pastoral as escapism inherently requires a degree of subjectivity, one that extends into the human figures so that they may represent the idylls of rural life. When coupled with the supreme realism of nature and structure, these characters therein become "real," as projections of the viewer.

Pastoral Landscape follows this paradigm. Influenced by the meticulous detailing of Flemish genre paintings and the spatial authority from the Italian Renaissance, Lorrain's scene provides a plausible, almost tangible vision. Lorrain was particularly renowned for his lustrous skies drawn from close observation: "[he would] lay in the fields before the break of day and until night in order to learn to represent very exactly the red morning sky, sunrise and sunset and the evening hours." "This close attention to a familiar subject is one of the main characteristics of Freilicher's work. From her apartment overlooking the city, Freilicher studied the urban landscape and brought its unwavering likeness into her paintings. When asked to paint "the American scene" by the Department of the Interior, Freilicher chose to paint from home as she had always done. ${ }^{7}$ The meticulously detailing between objects in her work sprout from this understanding of the space around her, even when abstracting her perspective. In the objects present in Parts of a World, Freilicher distinguishes separate depth between each aspect. When viewed as a whole, the relationship between pieces transcends the bounds of still-life and into a similar constructed iconography present in traditional pastorals.

It is never completely clear in Freilicher's paintings which objects are truly painted from life and which are conjured from past observations. While this may seem detrimental to analyzing symbolism in her work, it instead provides an integral lens. Everything is painted intuitively, positioned as her mind made connections. In Parts of a World, the first objects that emanate meaning together and separately are the statue and orchids. The small statue appears to be the icon Venus de Milo; the antique sculpture is ever-reproduced for its evocation of female sensuality and classical beauty. The sculpture itself is abstracted in consciousness throughout history, her lack of arms becoming an integral facet of her being, although she was originally constructed with them. ${ }^{8}$ Delicate like the statue, a pair of orchids hang over her head, their position mirroring the two buildings in the background. Both statue and flowers are painted with careful

\footnotetext{
${ }^{5}$ Alpers, What is Pastoral? 460.

${ }^{6}$ John Gage, Color and Culture: Practice and Meaning from Antiquity to Abstraction, 1st North American ed. (Boston: Little, Brown and Company, 1993): 167.

7 Jenni Quilter, "Explicit As a Star," Poetry 203, no. 4 (2014): 360-86, 375.

${ }^{8}$ Branko van Oppen, "Disarming Aphrodite: Rediscovering the Venus De Milo," Ancient History Encyclopedia. https://www.ancient.eu/article/1377/disarming-aphrodite-rediscovering-the-venusde-mil/.
} 
attention to the light that distinguishes each individual petal and curve of Venus' form. They are two fine, ancient objects brought into a 1980s New York City apartment. The sheer cloth beneath them adds to the misty illusion of time, binding together each artifact presented on the table.

Unlike the statue and flowers, the plate with fish evokes a sense of corporeality; out of every object in the scene, it is the fish that are most realistically painted, a sobering extension between the dream-like world and ours. Their slimy bodies and open eyes bring each piece of the scene together, including the viewer. As a result, the spiritual meaning is not to be ignored, particularly when observing Freilicher's past use of the imagery in works such as Loaves and Fishes. Fish stand as physical representations of our primordial existence, used by the Romans as symbols of the afterlife and later co-opted by Christianity to indicate Christ's ever-lasting life. ${ }^{9}$ In Freilicher's piece, each of these elements tie into its temporality, almost as projections of Freilicher's mind as she turns to the past to construct her present. Like the decaying antique castle in the background of Lorrain's pastoral, Freilicher's sunset city-scape seems otherworldly, only brought into reality through glimmers of personal objects like the blue plate and bowl of seashells. While Lorrain uses temporality to invite nostalgia, Freilicher abstracts it and presents the fragments of time that inform her identity and place in her home.

Freilicher's comfort in her urban environment is in almost complete opposition to Lorrain's $16^{\text {th }}$ century intentions. Although both escape into antiquity, Lorrain attempts to solidify its existence while Freilicher depicts its meta-physical fluctuation. In the industrialized environment of the late $19^{\text {th }}$ century, Impressionism emerged as a response to both capturing the present and accounting for its ever-changing movement. The brushstrokes in Paul Cézanne's The Bay of Marseilles Seen from L'Estaque (fig. 3) align with this ambition in depicting an urban landscape. Some buildings are hard-lined and structured with intention, while others are less defined. Cézanne's sky is leagues away from the strict realism of Lorrain's, its wide brushstrokes layering colors to construct a patchwork. Freilicher uses paint more similar to Cézanne's Post-Impressionism than her contemporaries. Her buildings and their shadows transition between each other with soft brushstrokes and flat paint, just as her objects do, as though they are all forced into reality from a hazy memory. There is an element of Freilicher's painting, however, that is more gestural than Cézanne and the other PostImpressionists.

Looking back to The Bay of Marseilles, Cézanne depicts a beloved view of his as he truly saw it: "Cezanne would leave out a great deal, including colors

\footnotetext{
${ }^{9}$ Peter Moyle, Marilyn Moyle, "Introduction to fish imagery in art, " Environmental Biology of Fishes 31 (Kluwer Academic Publishers, 1991): 5-23, 9.
} 
he felt were not expressive of the country...It would, in Cézanne's view, be more meaningful than the original scene." ${ }^{10}$ In this abstraction, his work becomes pastoral in its idealized environment. Furthermore, Cézanne's piece distinguishes itself separately from other Impressionists through his attention to the underlying geometrical compositions of nature and structure. By compiling a landscape of shapes, Cézanne paints with intention and reflection of the world as he saw it. Freilicher's work, though seemingly only figurative, employs a gestural approach like that of the Abstract Expressionists. Although different in formation than the likes of Jackson Pollock's drips, Freilicher's gestural abstraction of paint appears in its most philosophical form. Freilicher never sketched a scene before painting, always opting to intuitively construct as she moved about the canvas. Friend and poet James Schuyler once remarked that in her work, "the emotional force of an object is allowed its compositional weight...Structure is an improvisation, composed as painted, not a skeleton to be fleshed out." 11 It is possible that one or more elements in Parts of a World are imagined, their presence a testament to Freilicher's ability to create endless combinations of imagery. Where Freilicher's composition emulates fluidity of the present, Cézanne's "block-like brushstrokes" 12 act as a microscope into reality.

Cézanne's style in The Bay of Marseilles provided the groundwork to abstract artists in the early $20^{\text {th }}$ century, namely Cubism. Directly alluding to Cézanne, Georges Braque observed the same bay of Marseilles and translated its emotion into an abstraction of shapes. In Rio Tinto Factories at L'Estaque (fig. 4), Braque expands upon the precedent set by Cézanne, and completely explodes the scene into formulated edges. Instead of perceiving the mountains as in the horizon through linear perspective, the space becomes projected towards the viewer in fragments of dark and light. Here, we see the apex of the pictorial pastoral in modernity. With no overt visual cues to rely on, the viewer is forced to experience an intimate and individualized perspective. Although both play upon the ethos of pastoralism, it may appear as though Cubism is as far removed from Freilicher's figurative work as possible. However, they are embedded with the exact same intention: to paint objects not in their perfect form, but to paint how an object is represented. An attachment to the observed world is essential to abstracting it, just as manifesting an idealized location is essential to crafting an artificial identity. Braque's landscape escapes into an understanding of the world that we don't feel in Lorrain's Pastoral Landscape. His depth, his metaphysical nature, transcends

\footnotetext{
${ }^{10}$ Kenneth G. Johnston, "Hemingway and Cézanne: Doing the Country," American Literature 56, no. 1 (1984): 28-37, 30.

${ }^{11}$ Quilter, Explicit As a Star, 379.

12 "The Bay of Marseille, Seen from L'Estaque," The Art Institute of Chicago: European Painting and Sculpture. https://www.artic.edu/artworks/16487/the-bay-of-marseille-seen-from-l-estaque.
} 
the canvas and carries the viewer into a derealized space. Identity, therein, becomes one of the viewer's choosing.

Freilicher's space journeys through temporality as well, often choosing to paint her landscapes with a clear distinction between the inside and outside. A window-pane, or the rails of a balcony usually reinforce the position of the viewer as looking out into a separate world. In Parts of a World, this delineation is gone. There is a table, and objects on the table, but there is no other indication of where exactly the viewer stands. Behind the table, a defined stretch of orange paint gates in the scene-is this the ledge? Where Freilicher would normally place a shadow to add depth, the orange line instead cuts into a hazy, pale blue that stretches into the city-scape. To understand Freilicher's intention, it serves to observe one last facet of her abstract style: Color-Field.

Abstract Expressionism is often contextualized through its two branches of practice. One, as discussed earlier in the essay, is gestural abstraction. Jackson Pollock is an obvious representative of this, as his work often expresses the act of throwing paint onto a canvas. Freilicher exhibits certain elements of gesture in her work, but where she is most recognized with the Expressionists is in her use of color. Looking at a landscape abstracted through Color-Field by one of her contemporaries, Freilicher's work becomes less realistically figurative than assumed. Helen Frankenthaler painted her Mountains and Sea (fig. 5) from memory of her visit to Nova Scotia. ${ }^{13}$ On the right mid-section, a pool of pure blue stretches from a green mass, only defined in one portion by a jagged line pencil. The blue acts as the Atlantic Ocean, the green as a rocky cliff. Nowhere else in the painting is there such figuration. Nonetheless, the viewer still fathoms a sense of spatial meaning. How is this so? Frankenthaler's Mountains and Sea is argued to be the first Color-Field painting, ${ }^{14} \mathrm{a}$ form that would become the defining characteristic of work by artists such as Mark Rothko. Similar to the Cubist's endeavors to emancipate the mind through structured space, amorphous blots of color allow the viewer to conjure emotion separate from form. Specifically, Color-Field highlights the role of paint as a medium. Frankenthaler often stained the canvas with thinned paint, allowing the substance to operate free from the influence of her hand. Sections of Mountains and Sea show this innovation; strong, red paint dissolves into the canvas and becomes a softer pink, and traces of color spread around the piece as though still wet and expanding. Nothing about the work is heavy, much like the memory of a pleasant day at the beach.

\footnotetext{
13 “After 'Mountains and Sea': Frankenthaler 1956-1959," Guggenheim Museum Bilbao, https:/www.guggenheim-bilbao.eus/en/exhibitions/after-mountains-and-sea-frankenthaler-19561959.

14 Sybil E. Gohari, "Gendered Reception: There and Back Again: An Analysis of the Critical Reception of Helen Frankenthaler," Woman's Art Journal 35, no. 1 (2014): 33-39, 33.
} 
Although painted over half a century ago, the scene still breathes with life, allowing the feeling of nature to wash over the body even when viewed inside a museum in the city. The treatment of color in Parts of a World thereby supplies the same experience. Some spots are painted with authority and weight: the details on the petals; the shiny scales of the fish; the rumpled, sheer cloth. Others are more subtle, airier. Her city-scape in a copper sunset varies only slightly between hue. The buildings seem blurred and moveable, as if she offers the viewer to decide where and how it should be structured. The hazy blue, most in the form of Color-Field, reaches from the orange barrier and seeps into the city like smoke. Freilicher's flowers often mimic this extension, but this orchid drops down to cover the objects, sheltering them in place as the world around them wavers in subconscious suspension. Therefore, there is no true answer to what defines the spatial reality in Parts of a World. Even the figurative objects seem barely present, their forms subliminally temporal.

Using color to destabilize reality, Freilicher's still-life becomes fragmented, impressing upon the viewer whatever emotion it evokes. Considering the influences of pastoral imagery in Freilicher's work, the scene to her perhaps conjured a domain for which she was free to explore her place in the world around her. When observed under the lens of pastoralism, Freilicher's landscapes - both rural and urban - present an identity that is, in some ways, "innocent." The abstracted scene in Parts of a World is just that: parts of a world. There is no overt escapism like the traditional pastoral, no anxious grappling with identity. And yet, her painted world is incredibly pastoral.

During the summer of 1974, Jane Freilicher hosted a group of friends at her country-side home in East Hampton, Long Island. There, James Schuyler wrote a poem:

$$
\begin{aligned}
& \text { Enough to } \\
& \text { sit here drinking coffee, } \\
& \text { writing, watching the clear } \\
& \text { day ripen (such } \\
& \text { a rainy June we had) } \\
& \text { while Jane and Joe } \\
& \text { sleep in their room } \\
& \text { and John in his. I } \\
& \text { think I'll make more toast. }^{15}
\end{aligned}
$$

Freilicher's paintings capture this same contemplative beauty. A compilation of objects for no particular reason, an abstraction of an every-day view, an examination of color in light and shadow-all expressing Freilicher's

15 James Schuyler, “June 30, 1974,” Collected Poems (1995), 230. 
identity as a friend and artist. For Jane Freilicher and the parts of her world, it was enough to paint the simple pleasures of home, removed from the burdens of life in modernity.

\section{References}

“After 'Mountains and Sea': Frankenthaler 1956-1959.” Guggenheim Museum Bilbao. https://www.guggenheim-bilbao.eus/en/exhibitions/aftermountains-and-sea-frankenthaler-1956-1959.

"Opulent Beauty in a Homespun Environment: Jane Freilicher Paintings," Fine Art Connoisseur November 15, 2018. https://fineartconnoisseur.com/2018/03/fine-art-exhibition-jane-freilicherpaintings/

“The Bay of Marseille, Seen from L'Estaque." The Art Institute of Chicago: European Painting and Sculpture. https://www.artic.edu/artworks/16487/the-bay-of-marseille-seen-from-1estaque.

Alpers, Paul. "What Is Pastoral?" Critical Inquiry 8, no. 3 (1982): 437-60.

Ditner, David C. "Claude and the Ideal Landscape Tradition in Great Britain." The Bulletin of the Cleveland Museum of Art 70, no. 4 (1983): 147-63.

Gage, John. Color and Culture: Practice and Meaning from Antiquity to Abstraction. 1st North American ed. Boston: Little, Brown and Company, 1993.

Gohari, Sybil E. "Gendered Reception: There and Back Again: An Analysis of the Critical Reception of Helen Frankenthaler.” Woman's Art Journal 35, no. 1 (2014): 33-39.

Johnston, Kenneth G. "Hemingway and Cézanne: Doing the Country." American Literature 56, no. 1 (1984): 28-37.

Oppen, Branko van. "Disarming Aphrodite: Rediscovering the Venus De Milo." Ancient History Encyclopedia. https://www.ancient.eu/article/1377/disarming-aphrodite-rediscoveringthe-venus-de-mil/.

Peter Moyle, Marilyn Moyle. "Introduction to fish imagery in art." Environmental Biology of Fishes 31. Kluwer Academic Publishers, 1991. 5-23.

Quilter, Jenni. "Explicit As a Star." Poetry 203, no. 4 (2014): 360-86.

Rosenblum, Robert. "The Withering Greenbelt: Aspects of Landscape in Twentieth-Century Paintings." Denatured Visions: Landscape and Culture in the Twentieth Century. Harry N. Abrams: New York, 1992.

Schuyler, James. "June 30, 1974.” Collected Poems (1995), 230. 
Illustrations 


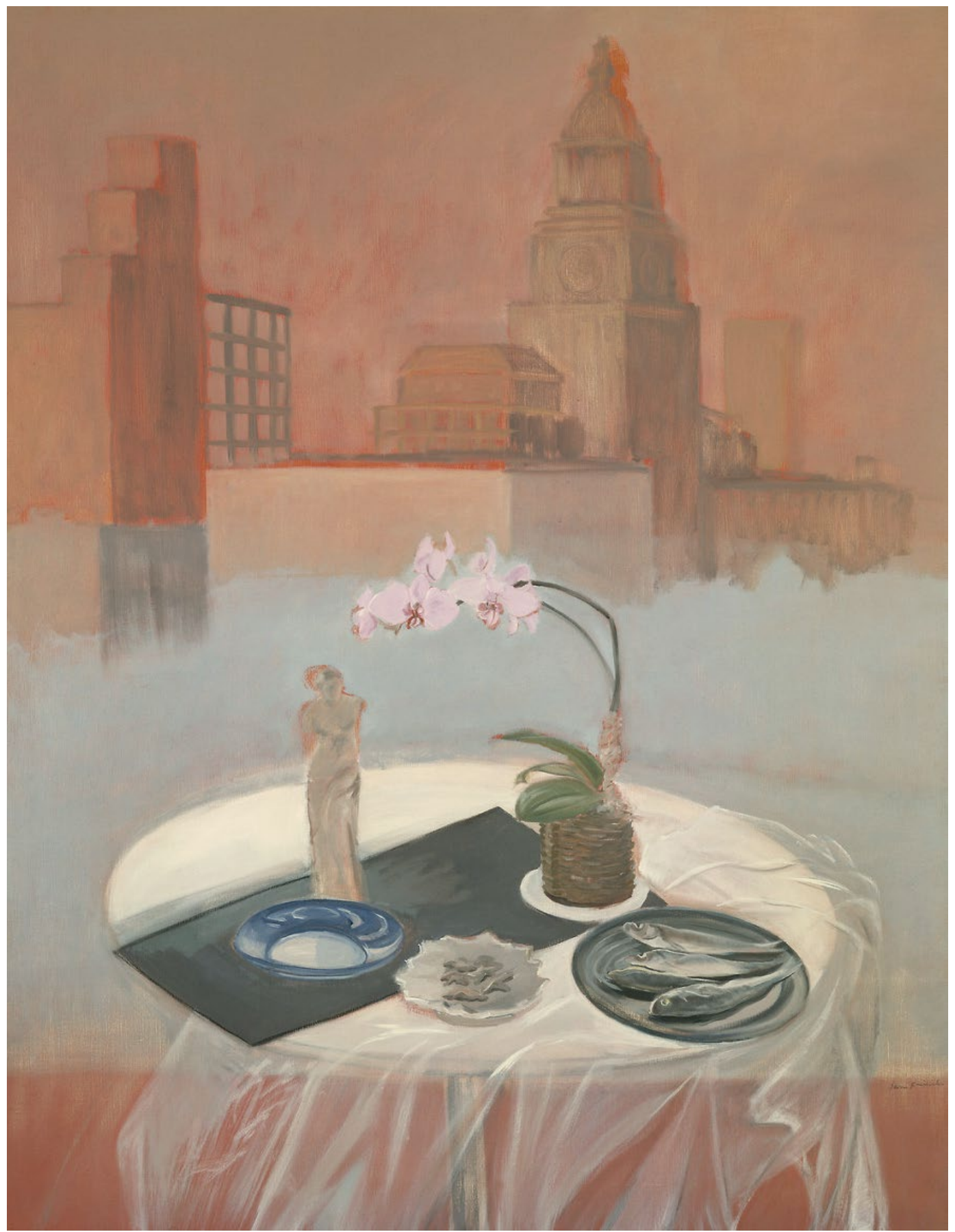

Figure 1. Parts of a World, Jane Freilicher, 1987. (Kasmin Gallery, New York City) 


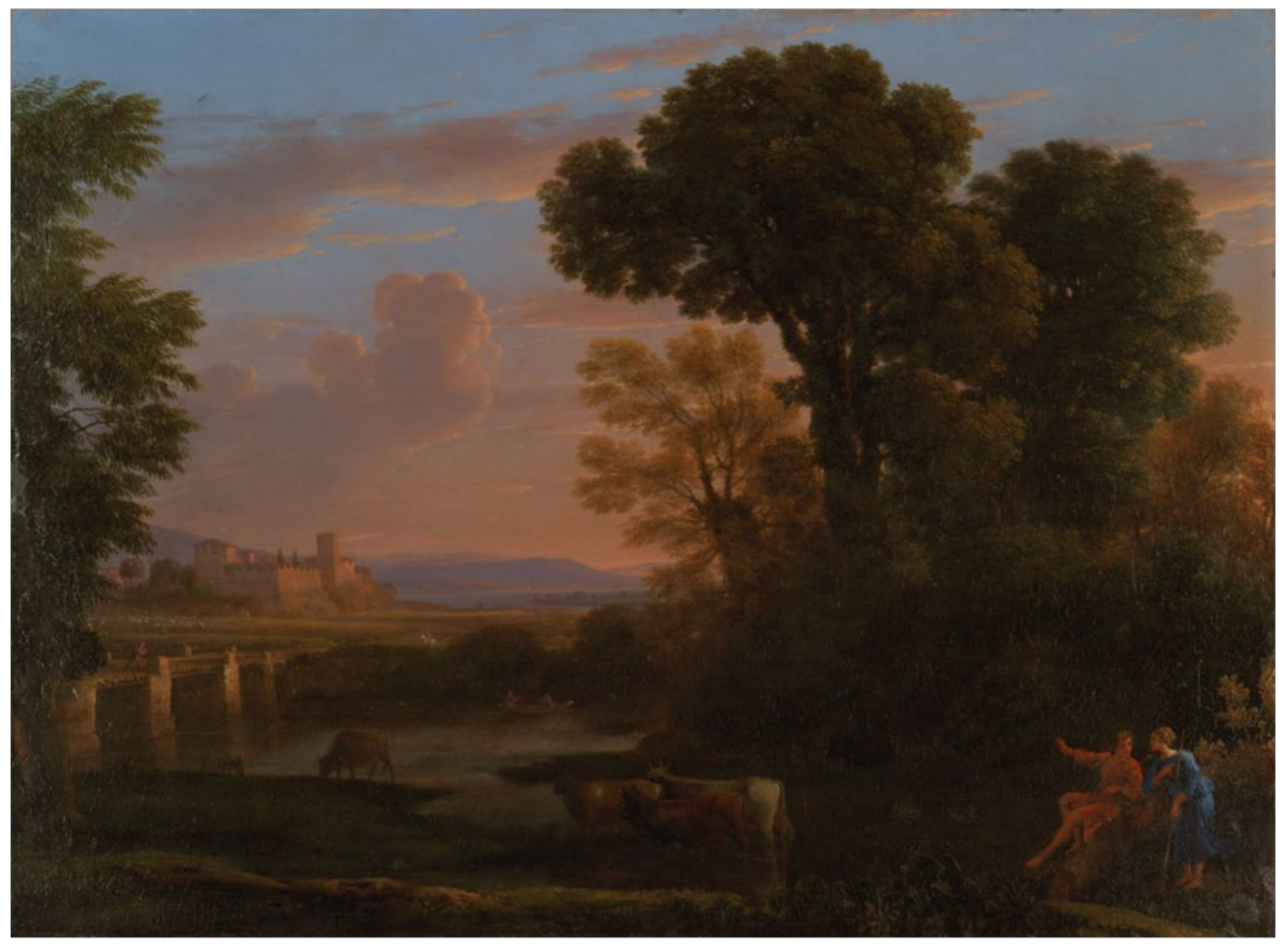

Figure 2. Pastoral Landscape, Claude Lorrain, 1648. (Yale University Art Gallery) 


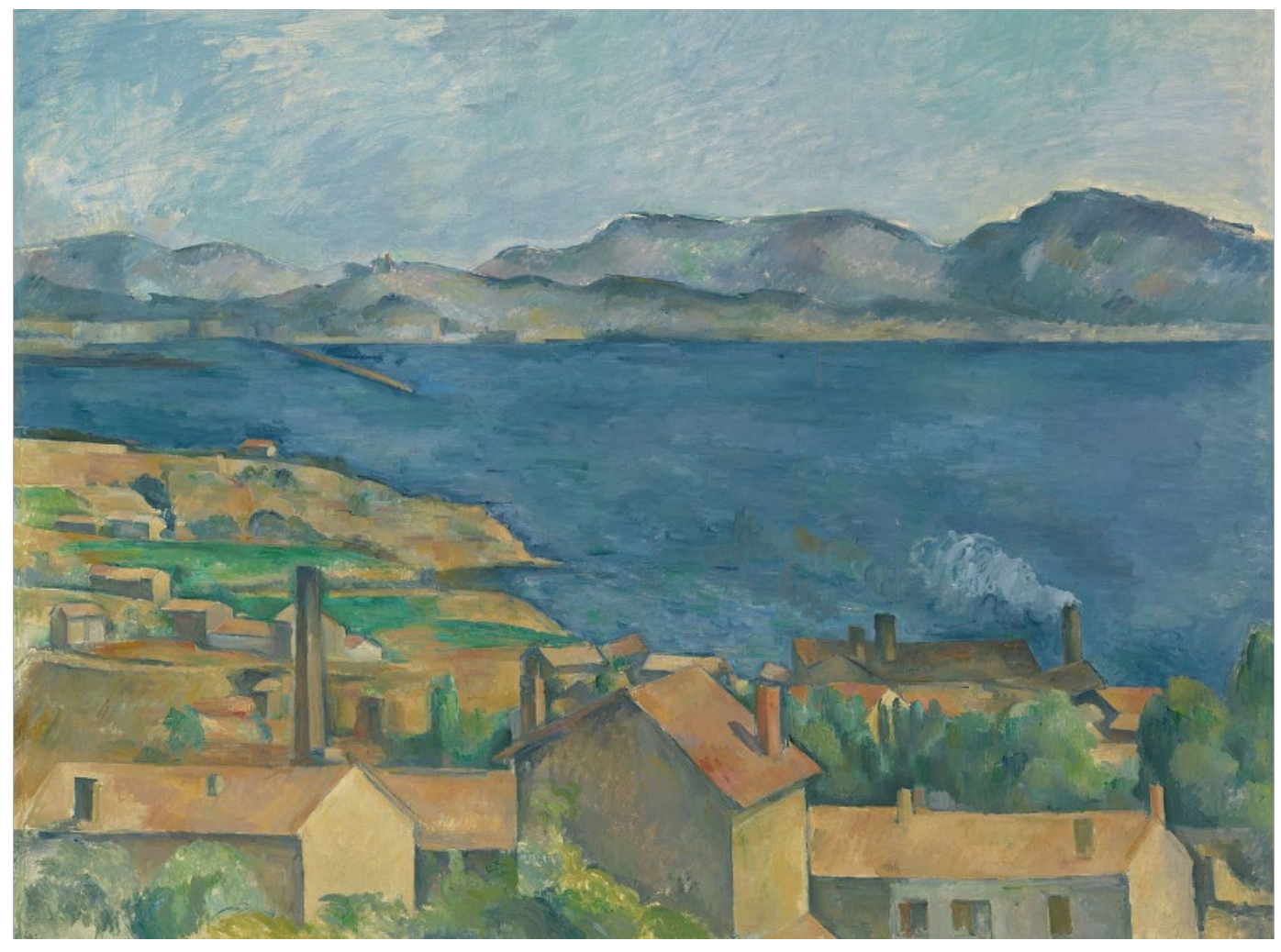

Figure 3. The Bay of Marseilles, Seen from L'Estaque, Paul Cézanne, 1885. (The Art Institute of Chicago) 


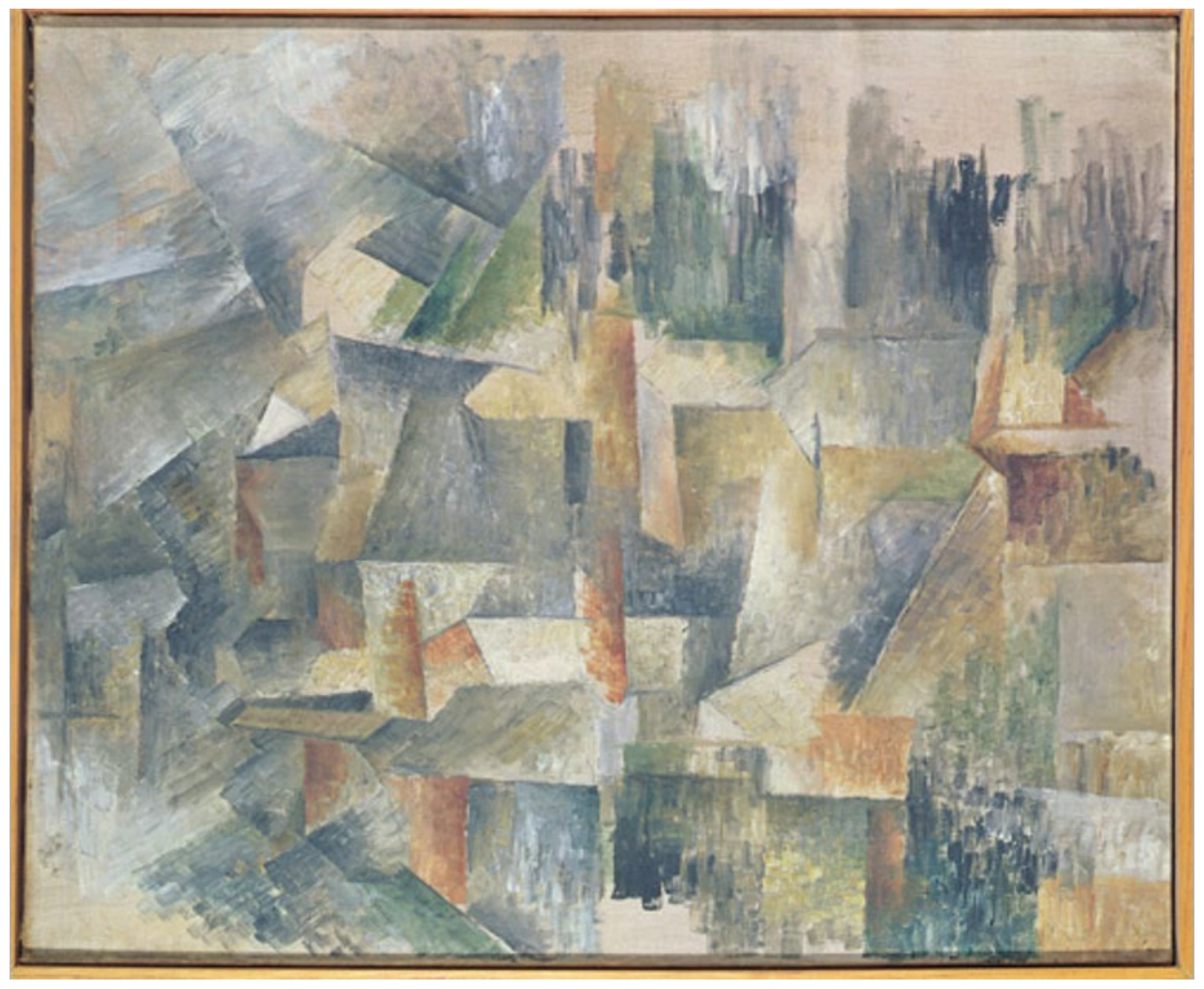

Figure 4. Rio Tinto Factory at L'Estaque, Georges Braque, 1910. (MIT library) 


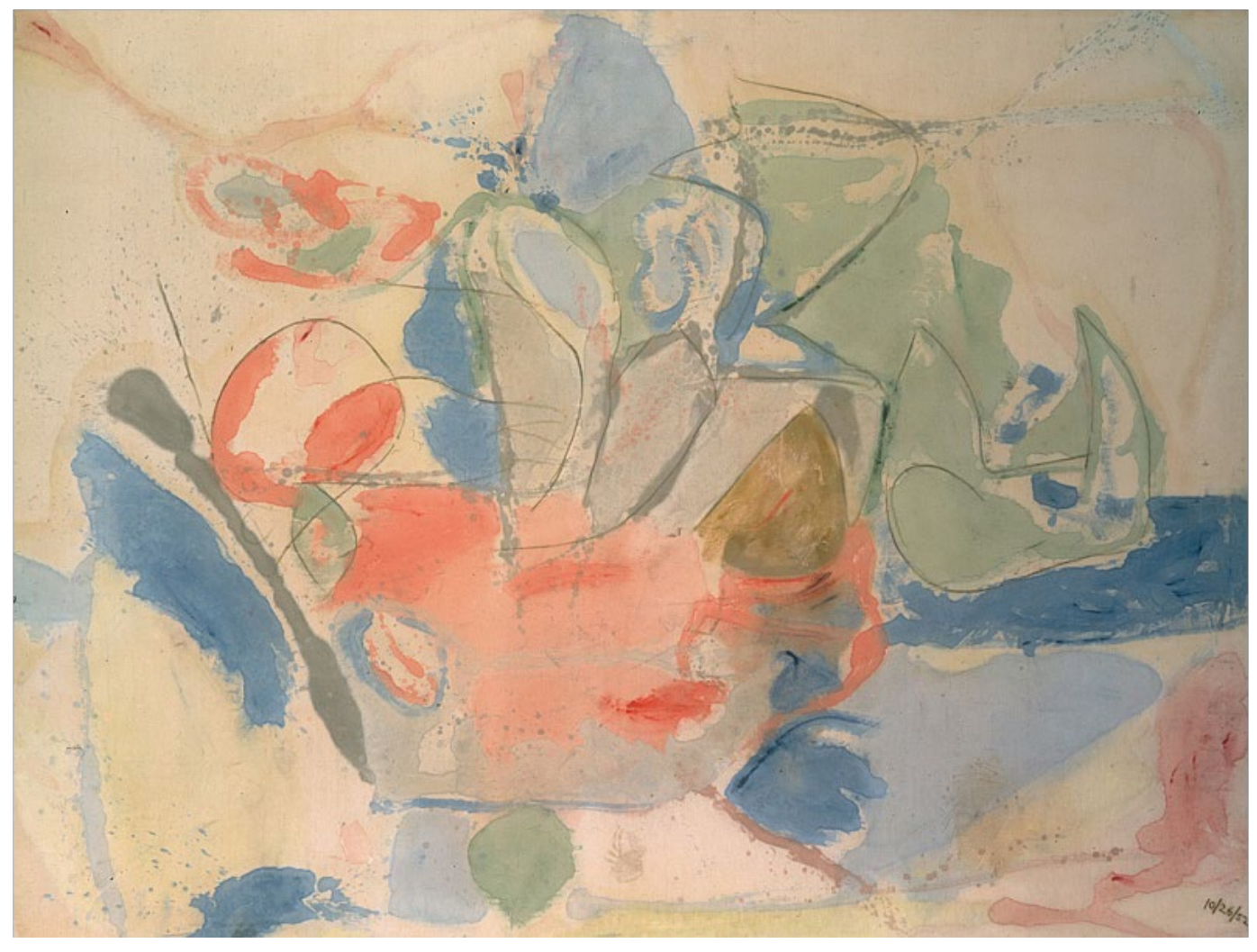

Figure 5. Mountains and Sea, Helen Frankenthaler, 1952. (National Gallery of Art, Washington) 